\title{
Polyadenylation releases mRNA from RNA polymerase II in a process that is licensed by splicing
}

\author{
FRANK RIGO ${ }^{1}$ and HAROLD G. MARTINSON ${ }^{1,2}$ \\ ${ }^{1}$ Department of Chemistry and Biochemistry, University of California at Los Angeles, Los Angeles, California 90095-1569, USA \\ ${ }^{2}$ Molecular Biology Institute, University of California at Los Angeles, Los Angeles, California 90095-1570, USA
}

\begin{abstract}
When transcription is coupled to pre-mRNA processing in HeLa nuclear extracts nascent transcripts become attached to RNA polymerase II during assembly of the cleavage/polyadenylation apparatus (CPA), and are not released even after cleavage at the poly(A) site. Here we show that these cleaved transcripts are anchored to the polymerase at their $3^{\prime}$ ends by the CPA or, when introns are present, by the larger $3^{\prime}$-terminal exon definition complex (EDC), which consists of splicing factors complexed with the CPA. Poly (A) addition releases the RNA from the polymerase when the RNA is anchored only by the CPA. When anchored by the EDC, poly(A) addition remains a requirement, but it triggers release only after being licensed by splicing. The process by which RNA must first be attached to the polymerase by the EDC, and then can only be released following dual inputs from splicing and polyadenylation, provides an obvious opportunity for surveillance as the RNA enters the transport pathway.
\end{abstract}

Keywords: RNA processing; cotranscriptional processing; transcript release; poly(A) signal; cleavage and polyadenylation; splicing; exon definition complex; coupling

\section{INTRODUCTION}

Most eukaryotic mRNAs are cleaved and polyadenylated in a reaction that is directed by a poly $(\mathrm{A})$ signal in the premRNA (Zhao et al. 1999). This same signal directs termination of transcription by RNA polymerase II (Whitelaw and Proudfoot 1986; Connelly and Manley 1988; Orozco et al. 2002). In addition, the poly(A) signal is involved in transcription elongation (Nag et al. 2006, 2007), in other pre-mRNA processing events such as capping and splicing (Niwa et al. 1990; Niwa and Berget 1991; Cooke and Alwine 1996; Flaherty et al. 1997; Dye and Proudfoot 1999; Vagner et al. 2000; Li et al. 2001; Kyburz et al. 2006; Millevoi et al. 2006), and with downstream events in mRNA production, such as export (Reed 2003; Schmid and Jensen 2008).

Emerging details on the assembly of the cleavage/polyadenylation apparatus (CPA) illustrate how intimately $3^{\prime}$ end processing is coupled with splicing and transcription. To direct cleavage at the poly(A) site, the CPA needs to assemble on the C-terminal domain (CTD) of the poly-

Reprint requests to: Harold G. Martinson, Department of Chemistry and Biochemistry, University of California at Los Angeles, 607 Charles E. Young Drive East, Box 951569, Los Angeles, CA 90095-1569, USA; e-mail: hgm@chem.ucla.edu; fax: (310) 206-4038.

Article published online ahead of print. Article and publication date are at http://www.rnajournal.org/cgi/doi/10.1261/rna.1409209. merase large subunit (McCracken et al. 1997; Hirose and Manley 1998; Fong and Bentley 2001; Ryan et al. 2002; Bird et al. 2004; Meinhart and Cramer 2004; Adamson et al. 2005; Zhang and Gilmour 2006). For most vertebrate mRNAs, which are both polyadenylated and spliced, this assembly is accomplished in the context of defining the $3^{\prime}$ terminal exon of the pre-mRNA (Berget 1995; Rigo and Martinson 2008). Vertebrate splicing generally proceeds via exon definition, in which the splice sites flanking each exon interact to assemble an exon definition complex (EDC) (Berget 1995; Sharma et al. 2008). In the case of $3^{\prime}$-terminal exons, for which the $3^{\prime}$ boundary is a poly(A) site, splicing factors at the $3^{\prime}$ splice site presumably combine with the CPA to assemble a "terminal EDC" (Fig. 1A; Berget 1995). Functional interactions between the terminal 3' splice site and the poly(A) site (Niwa et al. 1990; Niwa and Berget 1991; Antoniou et al. 1998; Li et al. 2001; Rigo and Martinson 2008) suggest that it is actually this larger composite structure, the $3^{\prime}$-terminal EDC, that is the functional entity responsible for carrying out the cleavage/polyadenylation reaction, and that participates in splicing.

Assembly of the $3^{\prime}$-terminal EDC occurs stepwise (Chao et al. 1999; Rigo and Martinson 2008) beginning with recognition of the $3^{\prime}$ splice site by splicing factors and finishing with the mature EDC firmly attached to the polymerase CTD (Fig. 1A; Rigo and Martinson 2008). The 

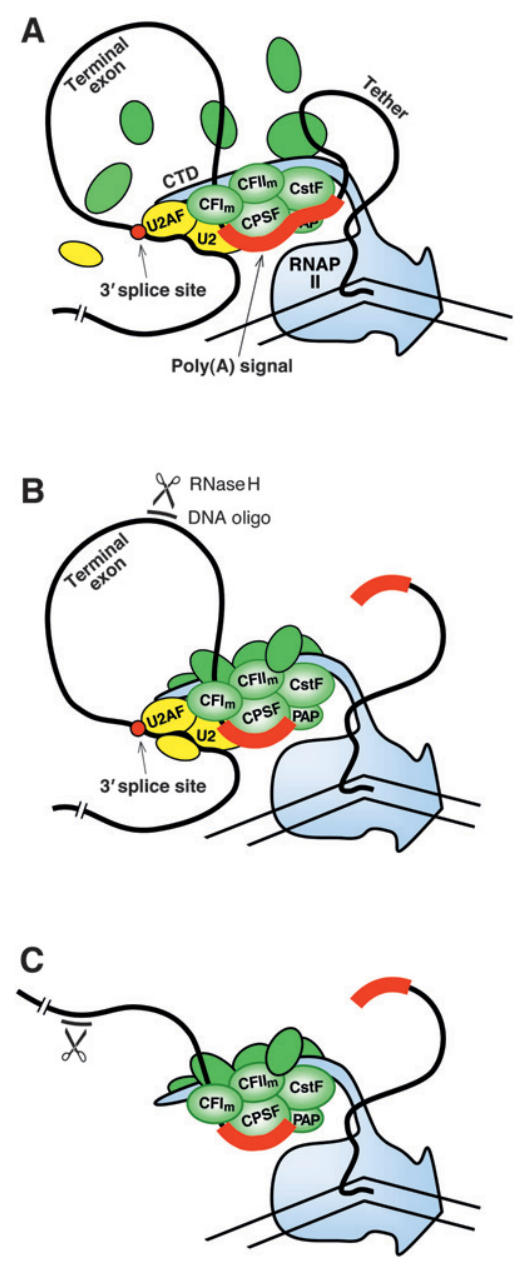

FIGURE 1. Cartoons of the presumptive $3^{\prime}$-terminal EDC and of the CPA. (A) Assembly of the 3'-terminal EDC (Berget 1995; Sharma et al. 2008). Only the core factors required for poly(A) site cleavage and $3^{\prime}$-terminal exon definition are labeled. The CPA is shown in green, and the splicing factors that interact with the CPA, and presumably combine with it to form the 3 '-terminal EDC, are shown in yellow. RNA polymerase II is shown in blue. The diagram accommodates the following known protein-protein and protein-RNA interactions: $\mathrm{CFI}_{\mathrm{m}}$ with $\mathrm{U} 2 \mathrm{AF}$ (Millevoi et al. 2006); CPSF with U2 snRNP (Kyburz et al. 2006); CFII $m$ and CstF with the CTD, with CPSF and with each other (Murthy and Manley 1995; de Vries et al. 2000; Fong and Bentley, 2001; Qu et al. 2006; Zhang and Gilmour, 2006); $\mathrm{CFI}_{\mathrm{m}}$ with $\mathrm{CFII}_{\mathrm{m}}$ and CPSF (Ruegsegger et al. 1996; de Vries et al. 2000; Venkataraman et al. 2005); and U2AF, U2 snRNP, $\mathrm{CFI}_{\mathrm{m}}$, CPSF, and CstF with the RNA (Zhao et al. 1999; Black, 2003; Brown and Gilmartin, 2003; Venkataraman et al. 2005). The placement of U2AF on the CTD of RNA polymerase II is arbitrary but is based on the fact that U2AF has been shown to bind tightly to the polymerase (Robert et al. 2002; Ujvari and Luse, 2004) except when the polymerase is isolated by use of a CTD-binding antibody which might displace the U2AF from the CTD (Das et al. 2007). SR proteins are not shown. (B) The EDC after poly(A) site cleavage. Poly(A) polymerase (PAP) is shown in this panel, interacting with CPSF (Kaufmann et al. 2004). PAP also interacts with U2AF (Vagner et al. 2000) and $\mathrm{CFI}_{\mathrm{m}}$ (Kim and Lee, 2001), but these interactions are not shown because of difficulties of depiction in two dimensions. The DNA oligo used for RNaseHcutting in Figure 2B and later experiments is shown. $(C)$ The CPA after poly(A) site cleavage. early phase of terminal EDC assembly likely involves multiple rearrangements on the surface of the polymerase (Nag et al. 2007), and is apparently very tenuous because, for assembly to be successful, the process must be stabilized by the RNA tether that links the poly $(\mathrm{A})$ signal to the polymerase (Fig. 1A; Bird et al. 2005; Rigo et al. 2005; Rigo and Martinson 2008). This tether serves to keep the poly(A) signal close to the polymerase CTD until the nascent EDC is sufficiently mature to cling to the CTD on its own. Subsequently, the RNA remains attached to the polymerase even after cleavage at the poly(A) site (Fig. 1B; Adamson et al. 2005; Rigo et al. 2005). Thus, the nascent mRNA, initially tethered to the polymerase at its growing $3^{\prime}$ end, remains attached to the polymerase by the EDC, even after its tether of nascent RNA has been severed at the poly(A) site.

It is not known when and how the EDC is dismantled to release the RNA from the polymerase CTD for transport to the cytoplasm. Transport away from the site of transcription is under stringent surveillance (Schmid and Jensen 2008), so release of the RNA from the polymerase CTD, either before or during transport, is likely to be carefully controlled. In mammalian cells, fluorescence in situ hybridization (FISH) studies show that many mutant RNAs with defects in processing also have defects in transport, and accumulate in discrete nuclear foci or "dots" at or near the transcriptional locus (Custódio et al. 1999, 2007; Johnson et al. 2000; Bird et al. 2005). Custódio et al. (1999) have suggested that this may reflect a failure of the RNA to be released from the polymerase CTD, which in turn, may be bound to the "nuclear matrix." Chromatin immunoprecipitation (ChIP) experiments in yeast show that RNA polymerase II can remain chromatin-associated even after termination of transcription (Morillon et al. 2003), raising the possibility that the Custódio et al. (1999) dots include RNA that fails to be released from terminated polymerases because of defective processing.

Here we have studied polymerase-attached, partially processed RNA, that has been cleaved at the poly $(\mathrm{A})$ site but not polyadenylated or spliced (Fig. 1B,C), and have asked whether it is released by subsequent steps in processing. This study was facilitated by an in vitro system using HeLa nuclear extracts in which both splicing and cleavage/polyadenylation are coupled to transcription and to each other (Rigo and Martinson 2008). We show that polyadenylation of poly(A)site-cleaved RNA can trigger release-but only if the RNA has no introns, so that $3^{\prime}$ attachment to the polymerase is mediated exclusively by the CPA (Fig. 1C). On the other hand, if the $3^{\prime}$ attachment is mediated by a terminal EDC (Fig. 1B), as for vertebrate pre-mRNAs with introns, then polyadenylation alone is not sufficient for release. Moreover, splicing alone also is not sufficient. For these RNAs both splicing, to dismantle the EDC, as well as polyadenylation, which targets the CPA, are required to permit release of the mature mRNA from the polymerase. 


\section{RESULTS}

\section{Poly(A)site-cleaved RNA is anchored to RNA polymerase II by the 3 '-terminal EDC}

During events leading up to poly(A) site cleavage, nascent RNA becomes attached to the transcription complex at the poly(A) signal (Fig. 1A) and remains attached even after cleavage has occurred (Fig. 1B; Rigo et al. 2005). To determine if attachment is mediated by the $3^{\prime}$-terminal EDC as shown in Figure 1B, we carried out coupled transcription-processing experiments followed by polymerase pull-downs (Fig. 2A) using a template described in Rigo et al. (2005). The RNA produced has a $3^{\prime}$ splice site upstream of the poly(A) signal (Fig. 2A), and is therefore expected to assemble a terminal EDC cotranscriptionally (Rigo and Martinson 2008). We began by looking at cleaved but nonpolyadenylated RNA (produced by adding $3^{\prime}$-dATP during processing, see Fig. 2A). Figure 2B, lanes 1 and 7, confirm that this RNA (Fig. 2B, band 1) co-IPs with the polymerase. Depending on the lot of antibody used, from $84 \%$ (Fig. 2B, lane 1) to $94 \%$ (Fig. 2B, lane 7) of the poly(A)site-cleaved RNA (Fig. 2B, band 1) was pulled down. We did not determine here whether these RNAattached polymerases were also template-engaged. Previous work has shown that poly(A)site-cleaved RNA does remain attached to ternary complexes (Rigo et al. 2005), but our pull-downs probably include terminated polymerases as well (Rigo et al. 2005; West et al. 2008).

To determine whether attachment of the RNA to the polymerase is mediated by the poly(A)site-cleaved $3^{\prime}$ ends of the RNA, we compared the pull-down efficiency of poly(A)site-cleaved RNA to that of a shorter internal reference RNA. This reference RNA was generated during the transcription-processing reaction by cutting some of the transcripts upstream of the poly(A) site with $\mathrm{RNaseH}$ (see Fig. 1B). Cutting was induced using a low concentration of DNA oligonucleotide to target the $\mathrm{RNaseH}$ in the extract to a position $181 \mathrm{nt}$ upstream of the poly(A) cleavage site (Figs. 1B, 2B, band 2). The results (Fig. 2B, lanes 1,2) show that the poly(A)site-cleaved transcripts (Fig. 2B, band 1) co-IP with the polymerase much more efficiently than the truncated RNA lacking poly(A)site-cleaved $3^{\prime}$ ends (Fig. $2 \mathrm{~B}$, band 2), giving a band 1 to band 2 ratio that was six times larger for the pellet (Fig. 2B, lane 1) than for the supernatant (Fig. 2B, lane 2) when we used lot L antibody, and 13 times larger for lot I antibody (Fig. 2B, lanes 7,8). This pellet/supernatant ratio (the pull-down efficiency) indicates that RNA with poly(A)site-cleaved $3^{\prime}$ ends binds up to 13 -fold better to the polymerase than does RNA cut a short distance upstream with RNaseH.

Since attachment of poly(A)site-cleaved RNA to the polymerase depends on the presence of the poly $(\mathrm{A})$ sitecleaved $3^{\prime}$ end, an intact EDC, that survives cleavage, may be responsible for the attachment (Fig. 1B). We interrogated
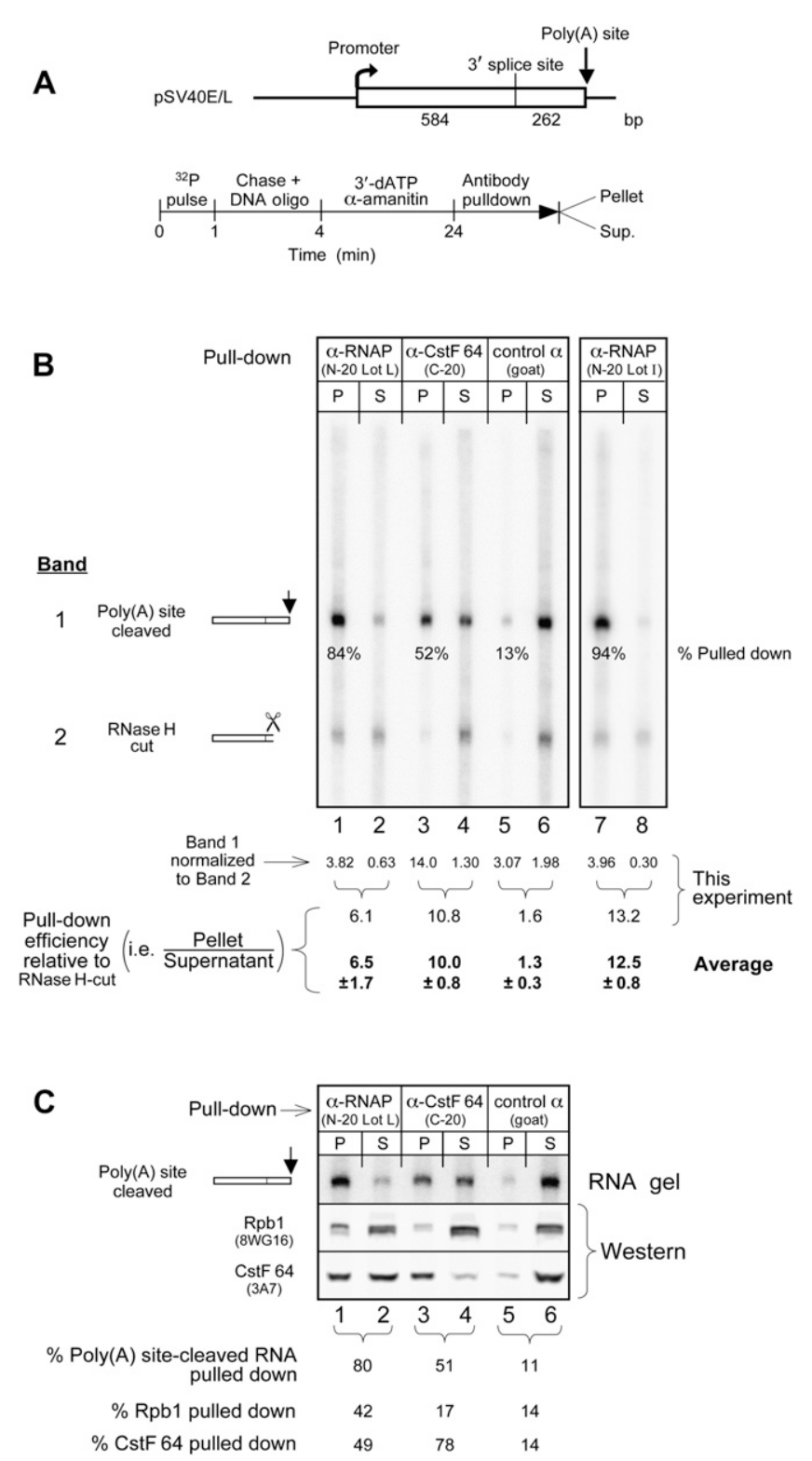

FIGURE 2. EDC-mediated attachment of poly(A)site-cleaved RNA to RNA polymerase II. $(A)$ The plasmid construct and the outline of the experimental protocol (Rigo et al. 2005). (B) Pull-down of poly (A)site-cleaved RNA (Method 1). The DNA oligo for RNaseH cutting was CCATCTTCTGCCAGG $\left(5^{\prime} \rightarrow 3^{\prime}\right)$ at $1 \mathrm{ng} / \mu \mathrm{L}$. The concentration of this oligo was chosen so that only a small proportion of the transcripts would be cut by RNaseH at this upstream location. For lanes 1 and 2 the polymerase antibody used was N-20, lot L1407. Lanes 7 and 8 are from a different experiment using antibody from lot I0706. For lanes 1, 2, 5, and 6 the average and standard deviation are given for the experiment shown plus two additional independent experiments. For lanes 3 and 4 the average and range are given, for this and one additional independent experiment. For lanes 7 and 8 the average and range are for duplicates within the same experiment. The lane 7 and 8 data are not included in the average for lanes 1 and 2. (C) The amount of RNAPII and CstF pulled down concomitant with poly(A)site-cleaved RNA. The experiment was carried out as for part $B$ except that each reaction was scaled up by twofold and then split in half for the RNA or the Western analysis. For simplicity, only the poly(A)site-cleaved RNA and the relevant protein bands are shown. 
the EDC by monitoring the ability of CstF to pull down poly(A)site-cleaved RNA. CstF binds the poly(A) signal downstream of the poly(A) cleavage site and would therefore not be expected to pull down the cleaved RNA unless the EDC remains substantially intact (Fig. 1A,B). Figure 2B, lane 3, confirms, as shown previously with a different extract (Rigo et al. 2005), that CstF pulls down poly(A)sitecleaved transcripts (Fig. 2B, band 1). This result is consistent with the possibility that the EDC remains intact after poly(A) site cleavage of the RNA.

Despite the obvious ability of poly(A)site-cleaved RNA to co-IP with CstF (Fig. 2B, lane 3, band 1), about half of the poly $(\mathrm{A})$ site-cleaved RNA remained in the supernatant (Fig. 2B, lane 4). This differs from the polymerase pulldowns where most of the poly(A)site-cleaved RNA was pulled into the pellet (Fig. 2B, lanes 1,7). To determine if this reflects differences in antibody pull-down efficiencies we repeated the experiment of Figure $2 \mathrm{~B}$, but with the addition of a Western blotting step to analyze the immunoprecipitates for both RNA and protein (Fig. 2C). Unexpectedly, we found that while $80 \%$ of the poly(A)sitecleaved RNA was pulled down by polymerase antibody in this experiment (using the lot L antibody, as in Fig. 2B, lanes 1,2 ), only $42 \%$ of the total polymerase in the transcription mixture was pulled down (Fig. 2C, lanes 1,2). Evidently, polymerases carrying poly(A)site-cleaved RNA are preferentially accessible to the antibody. Interestingly, the converse was true for CstF (Fig. 2C, lanes 3,4). About half of the poly(A)site-cleaved RNA was pulled down by CstF antibody (as in Fig. 2B, lanes 3,4), but this was considerably less than the $78 \%$ of total CstF that was pelleted in the pull-down. The simplest explanation for this result, consistent with results to be presented later, is that the CstF that is associated with poly(A)site-cleaved RNA is less accessible to this antibody than is the bulk CstF in the extract. Alternatively, half of the poly(A)site-cleaved complexes may have lost their CstF.

The pull-downs in Figure 2, B and C, were done with a large excess of antibody so as to maximally pull-down the poly(A)site-cleaved RNA. However, for routine experiments we generally used much less antibody. As shown in Figure $3 \mathrm{~A}$ the overall conclusions remain the same under these conditions. Thus, lanes 1 and 2 in Figure 3A show, in agreement with lanes 1 and 2 in Figure 2B, that RNA with poly(A)site-cleaved 3' ends (Fig. 3, band 2) binds much better to the polymerase (fivefold in Fig. 3A) than does the reference RNA cut with RNaseH. Figure $3 \mathrm{~A}$, lanes 5 and 6, similarly confirms that CstF pulls down poly(A)site-cleaved transcripts (band 2) preferentially as discussed above for Figure 2B (lanes 3,4, band 1 ). Thus, by normalizing to the RNaseH-cut RNA, the conclusions from the experiments become independent of the amount of antibody used and the absolute pull-down efficiencies.

The selective attachment of poly(A)site-cleaved RNA to the polymerase is additionally indicated, in Figure 3A, by comparison to the very long RNA (more of which was produced in this experiment) at the top of lanes 1 and 2 (Fig. 3A). This RNA, like the RNaseH-cut RNA in band 3 , does not co-IP with the polymerase nearly as efficiently as the poly $(\mathrm{A})$ site-cleaved RNA in band 2. The long RNA obviously differs from the poly(A)site-cleaved RNA in not having successfully assembled a $3^{\prime}$-end processing apparatus capable of cleaving the RNA (Rigo et al. 2005). Thus, neither long RNA that remains uncleaved, nor shorter RNA that lacks a native 3 '-end, are associated with an apparatus that can bind them tightly to the polymerase, as is the case for RNA that has been cleaved at the poly (A) site.

\section{Poly(A) addition does not release poly(A)site-cleaved RNA from the 3 '-terminal EDC}

Remarkably, even after addition of a poly(A) tail to the poly(A)site-cleaved RNA it was still pulled down by the polymerase (Fig. 3A, lane 3, band 1). Indeed, after normalization to the RNaseH-cut reference RNA (band 3), the average pull-down efficiency (Fig. 3A, pellet/supernatant ratio) of the cleaved and polyadenylated RNA (Fig. 3A, band 1, lanes 3,4) was the same (5.0) as that of the cleaved RNA lacking a poly(A) tail (Fig. 3A, band 2, lanes 1,2). When the pull-down efficiency for cleaved and polyadenylated RNA (Fig. 3A, lanes 3,4) was expressed as a ratio to that for cleaved but nonpolyadenylated RNA (Fig. 3A, lanes 1,2$)$ in each of two experiments, and then averaged, the result was 1.0 (Fig. 3A). Thus, poly(A) tail addition does not affect the binding of EDC-attached, poly(A)sitecleaved RNA to the polymerase.

\section{The CPA is sufficient to retain poly(A)site-cleaved RNA on the polymerase}

The RNA in Figures 2 and 3A has a 3' splice site upstream of the poly(A) signal and is presumed to assemble a terminal EDC during preparations for $3^{\prime}$-end processing (Fig. 1A). Factors that bind the $3^{\prime}$ splice site include proteins that also associate with the CPA and the polymerase to form this EDC (Fig. 1A). We wondered whether the 3' splice site associated proteins, as part of the EDC, play a role in securing poly(A)site-cleaved RNA to the polymerase. To test this we mutated the $3^{\prime}$ splice site, which would preclude assembly of a full EDC while still allowing CPA formation (see Fig. 1C), and then repeated the polymerase pull-down on cleaved but nonpolyadenylated RNA. As expected the poly(A)site-cleaved RNA with a wild-type 3 ' splice site was pulled down efficiently (Fig. 3B, lane 1, band 2). Significantly, the poly(A)site-cleaved RNA with a mutant $3^{\prime}$ splice site was also pulled down efficiently (Fig. $3 \mathrm{~B}$, lane 3 , band 2) indicating that the CPA alone is sufficient to attach the poly(A)site-cleaved RNA to the polymerase. 


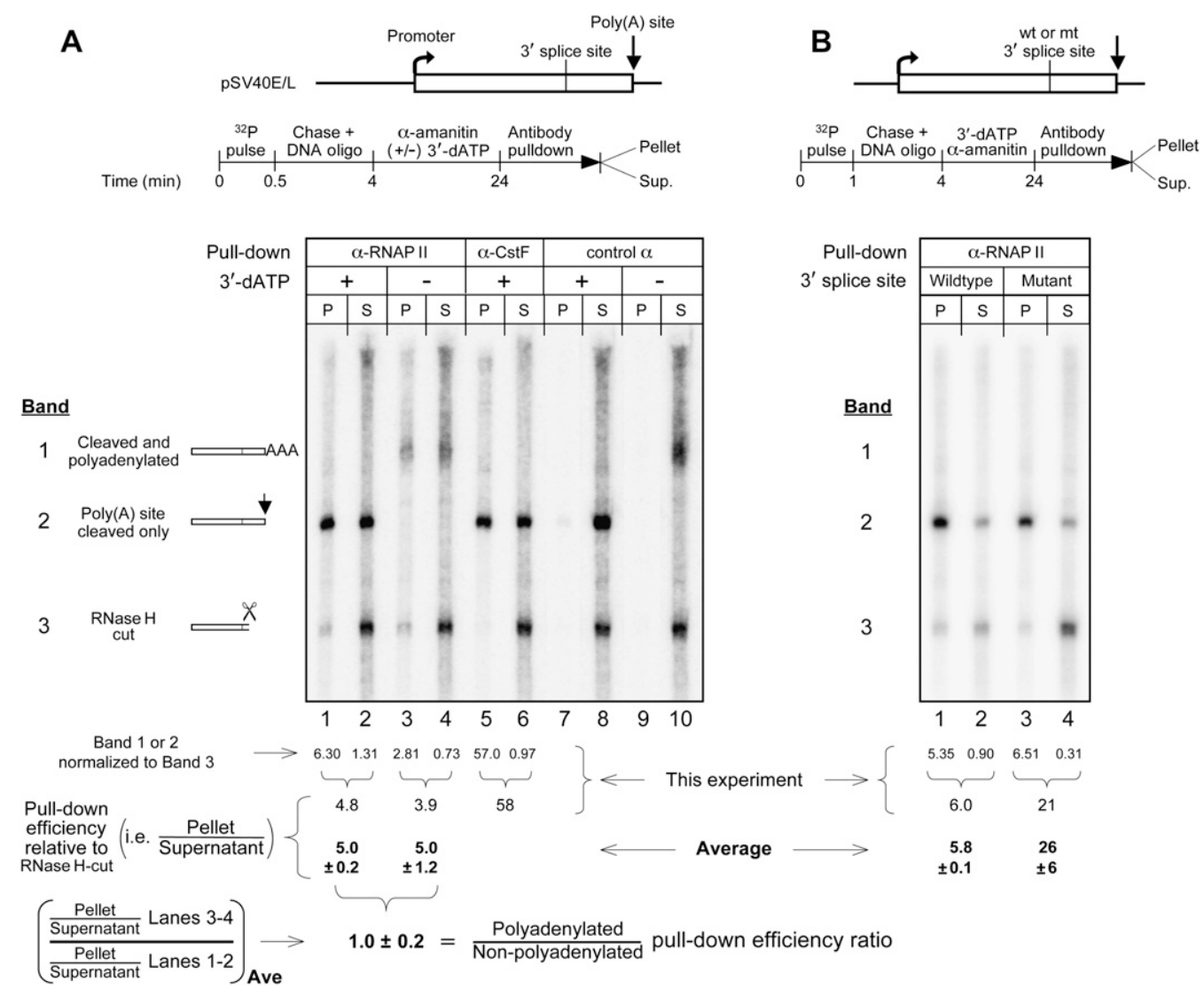

FIGURE 3. Both the EDC and the CPA attach poly(A)site-cleaved RNA to the polymerase, and polyadenylation does not release the EDC-attached RNA. (A) Pull-down (Method 2) of EDC-attached poly(A)site-cleaved RNA that either is or is not polyadenylated. Band 1 in lanes 3 and 4 was quantitated after subtracting the background appearing at the same position in lanes 1 and 2 , respectively. The averages and ranges for two independent experiments are shown. (B) Pull-down of poly(A)site-cleaved RNA (Method 3) that either has or does not have a 3' splice site. For lanes 3 and 4 a plasmid construct with a mutant $3^{\prime}$ splice site $(\mathrm{AG} \rightarrow \mathrm{ct})$ was used. The averages and ranges for two independent experiments are shown.

Although the contribution of $3^{\prime}$ splice site-associated proteins to the attachment of RNA to the polymerase is of marginal significance in the presence of the CPA (Fig. 3B, band 2), the binding activity of these proteins can be dissected free of the overwhelming contribution of the CPA by truncating the RNA upstream of the poly(A) site. Accordingly, Figure 3B shows that RNaseH-cut RNA, though inefficiently pulled down even with a wild-type $3^{\prime}$ splice site (Fig. 3B, lanes 1,2, band 3), was pulled down discernibly less efficiently when the $3^{\prime}$ splice site was mutated (Fig. 3B, lanes 3,4, band 3). Interestingly, this had the indirect effect of significantly increasing the normalized pellet/supernatant ratio for the mutant pull-down in lanes 3 and 4 (Fig. 3B, cf. mutant pellet/supernatant of 26 and wild-type pellet/supernatant of 5.8), reflecting the very inefficient pull-down of the mutant $\mathrm{RNaseH}$-cut RNA. Thus, these results reveal a weak ability of the $3^{\prime}$ splice site associated proteins to attach RNA to the polymerase in the absence of the CPA, but show that these proteins do little to augment binding when the CPA is present. In addition, the large pellet/supernatant ratio for the mutant $\mathrm{RNaseH}$-cut RNA emphasizes the robustness of the CPA-polymerase attachment under conditions where the $3^{\prime}$ splice site binding proteins are not involved.

\section{RNA attached to the polymerase exclusively by the CPA is released by polyadenylation}

Although Figure 3A showed that poly(A) addition does not encourage release of EDC-attached poly $(\mathrm{A})$ site-cleaved RNA from the polymerase (Fig. 3A, lanes 1-4, pull-down efficiency ratio $=1.0$ ), we wondered whether RNA attached only by the CPA might be released by polyadenylation.

To address this question we repeated the experiment of Figure $3 \mathrm{~A}$, lanes 1-4, except that we used transcripts with mutant $3^{\prime}$ splice sites that can assemble a CPA (Fig. 1C) but not an EDC. In preparing for this experiment we discovered that poly(A) tail length-control is compromised on the mutant $3^{\prime}$ splice site RNA, and the smears of heterogeneously polyadenylated RNA were difficult to quantitate against the background of nonpolyadenylated RNA in the gel (see Supplemental Fig. S1 for further analysis). We therefore did an oligo $(\mathrm{dT})$ selection to isolate the polyadenylated RNA for more reliable quantitation. Of course, 
this precluded the use of RNaseH-cut RNA (which is not polyadenylated) as an internal standard. Therefore, we simply compared, in parallel samples, the pull-down efficiencies of mutant $3^{\prime}$ splice site RNAs that were either cleaved and polyadenylated (Fig. 4, lanes 3,4), or cleaved but not polyadenylated (Fig. 4, lanes 1,2), because we know that the latter remain attached to the polymerase (Fig. 3B, lanes 3,4$)$. Although the use of an internal standard was not possible in these experiments, we have found, despite the variation in pull-down efficiencies between experiments, that these efficiencies are nevertheless fairly consistent across samples within any experiment.

Figure 4 shows that the addition of a $\operatorname{poly}(\mathrm{A})$ tail does indeed cause release of CPA-attached RNA from the polymerase. The pull-down efficiency for polyadenylated CPA-attached RNA (Fig. 4, lanes 3,4) was only one third (31\%) of that for poly(A)site-cleaved RNA (Fig. 4, lanes 1,2). Thus, while the addition of a poly(A) tail has little or no effect on the ability of the EDC to retain the RNA on the polymerase (Fig. 3A, polyadenylated/nonpolyadenylated ratio $=1.0)$, in the case of the CPA, retention of the RNA on the polymerase is dramatically reduced by poly $(\mathrm{A})$ addition (Fig. 4, polyadenylated/ nonpolyadenylated ratio $=0.31)$. We also compared the CPA-attached polyadenylated RNA pull-down efficiency directly with that of EDC-attached polyadenylated RNA in

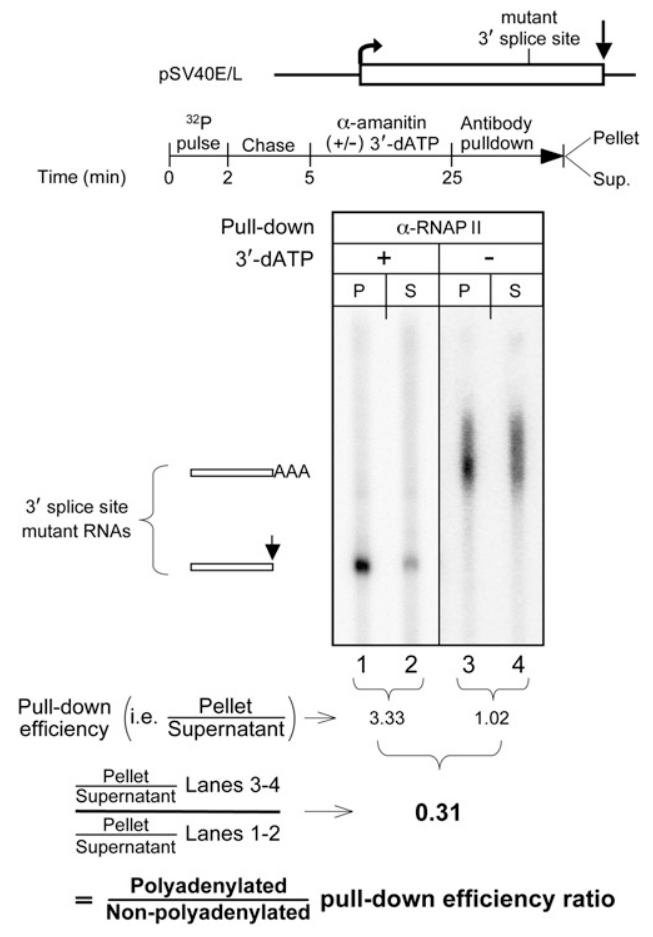

FIGURE 4. Polyadenylation releases RNA whose only attachment to the polymerase is through the CPA. Pull-down Method 1 was used. A construct with a mutant $3^{\prime}$ splice site $(\mathrm{AG} \rightarrow \mathrm{ct})$ was used. The RNA in lanes 3 and 4 was oligo(dT) selected prior to loading on the gel. an experiment comparable to that of Figure $3 \mathrm{~B}$, and found that the polyadenylated CPA-attached RNA was pulled down much less efficiently (Supplemental Fig. S1). Indeed, the result agrees quantitatively with Figure 4 (see analysis in Supplemental Fig. S1) and confirms that polyadenylation releases RNA from the polymerase when it is attached by the CPA alone.

\section{Splicing has little effect on attachment of poly(A)site-cleaved RNA to the 3 '-terminal EDC}

The pSV40E/L transcripts used for the experiments of Figures 2 and 3 contain a $3^{\prime}$ splice site that can interact with the poly(A) signal to form an EDC, but they cannot splice because they have no $5^{\prime}$ splice site. We wondered whether the $3^{\prime}$-terminal EDC of an RNA that contains spliceable introns would attach RNA to the polymerase like the orphan EDC of pSV40E/L, and whether polymerase attachment would be affected by splicing.

To address these questions we turned to our $\beta$-globin splicing construct, $\mathrm{p} \beta \Delta$-L (diagrammed in Figure 5). First we repeated all of the experiments in Figure 3A using $\mathrm{p} \beta \Delta-\mathrm{L}$ in place of SV40E/L. Supplemental Figure S2 confirms that, as for $\mathrm{pSV} 40 \mathrm{E} / \mathrm{L}$, poly $(\mathrm{A})$ site-cleaved $\mathrm{p} \beta \Delta$-L transcripts are attached to the polymerase at their $3^{\prime}$ ends through an EDC that remains sufficiently intact to contain CstF, and that this attachment is not affected by the addition of a poly(A) tail. Supplemental Figure S3 confirms that the CPA assembled on transcripts of a $\mathrm{p} \beta \Delta$-L derivative ( $\mathrm{p} ß \mathrm{CDNA}-\mathrm{L}$ ) lacking splice sites, like the CPA on pSV40E/L 3'-splice-site mutant transcripts (Fig. 3B), is sufficient to retain poly(A)site-cleaved RNA on the polymerase.

Having confirmed for $\mathrm{p} \beta \Delta$ - $\mathrm{L}$ that polyadenylation does not release poly(A) site-cleaved transcripts from the polymerase, we next asked whether splicing could cause the poly(A) site-cleaved transcripts to be released. Splicing for both introns of the $\mathrm{p} \beta \Delta$-L transcripts takes place after 3 '-end processing in our in vitro system (Rigo and Martinson 2008). Figure 5 illustrates an intermediate time point in the splicing phase of the reaction, where some fully spliced RNA had already been produced, but a significant amount of completely unspliced precursor was still present. We used this mixture to compare the efficiencies with which the fully spliced and the fully unspliced poly $(\mathrm{A})$ sitecleaved RNAs were pulled down by the polymerase.

To compare pull-down efficiencies we expressed the band intensities of the fully spliced and the fully unspliced RNAs as a ratio, and then asked whether this ratio differed between supernatant and pellet (Fig. 5). The results showed that there was little difference in this ratio between supernatant and pellet, suggesting that splicing has little effect on the attachment of $\operatorname{poly}(\mathrm{A})$ site-cleaved RNA to the polymerase. However, because it is known that spliceosomes associate with the polymerase CTD in vitro and that this association is disrupted by splicing (Zeng and Berget 2000), 

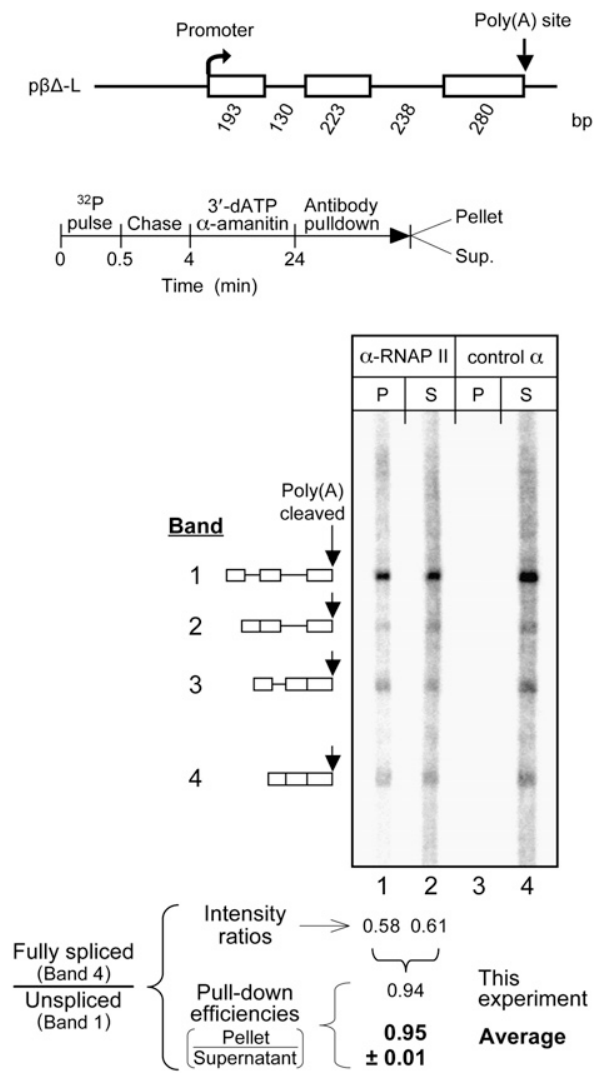

FIGURE 5. Splicing of EDC-attached, nonpolyadenylated RNA has little effect on release from the polymerase. Pull-down Method 2 was used. The average and range for two independent experiments is shown.

we conducted a more thorough analysis of the data taking each intron separately. The results are consistent with a small contribution by the spliceosome on intron 1 to the attachment of $\mathrm{p} \beta \Delta$-L RNA to the polymerase (see Supplemental Fig. S3).

\section{Splicing releases polyadenylated RNA from the 3 '-terminal EDC}

The failure of splicing to have a substantial effect on attachment of RNA to the polymerase by the 3 '-terminal EDC was not unexpected. Presumably the ejection of splicing factors from the EDC by splicing leaves behind a CPA (Fig. 1, cf. B and C) which, as we have shown, can retain cleaved but nonpolyadenylated RNA on the polymerase (Fig. 3B; Supplemental Fig. S3A). If retention of nonpolyadenylated RNA on the polymerase after splicing really is due to a residual CPA, then EDC-attached RNA that is polyadenylated should be released from the EDC by splicing, because the CPA that remains after splicing is not expected to efficiently retain RNA that has a poly(A) tail (Fig. 4; Supplemental Fig. S1). Thus, although polyadenylation alone does not release RNA from the EDC (Fig. 3A, lane 3; Supplemental Fig. S2), and splicing alone does not release RNA from the EDC (Fig. 5), polyadenylation followed by splicing is predicted to release the RNA.

To test the prediction that polyadenylated RNA will be released from the EDC by splicing we carried out an experiment like that of Figure 5, but without the use of $3^{\prime}$ dATP (Fig. 6). To restrict the analysis to transcripts that were already fully polyadenylated we oligo(dT) selected the RNA prior to gel electrophoresis. Figure 6, lane 1, shows that the unspliced, polyadenylated precursor (Fig. 6, band 1) from this splicing construct is pulled down by the polymerase with an efficiency comparable to that of the nonsplicing construct of Figure 3A (both using Method 2). In contrast to the efficient pull-down of the unspliced RNA, little of the fully spliced mRNA (Fig. 6, band 4) was pelleted, and Figure 6, lane 2, shows that most of this remains in the supernatant. The simplest interpretation of this result is that fully spliced and polyadenylated RNA is efficiently released from the polymerase.

We also carried out CstF pull-downs. We showed previously that CstF pulls down poly(A)site-cleaved RNA (Fig. 2B,C, lane 3; Supplemental Fig. S2, lane 5). Figure 6 (lane 3, band 1) shows that this is true even after the RNA has been polyadenylated. Presumably this reflects the continued integrity of the EDC through which the CstF is connected to the RNA (Fig. 1B). However, once the spliced and polyadenylated RNA is released, and is no longer associated with the EDC, CstF should not be able to pull it down. The results of Figure 6, lanes 3 and 4, fit this prediction, and show that splicing is accompanied by a reduced ability of CstF to pull down the polyadenylated RNA.

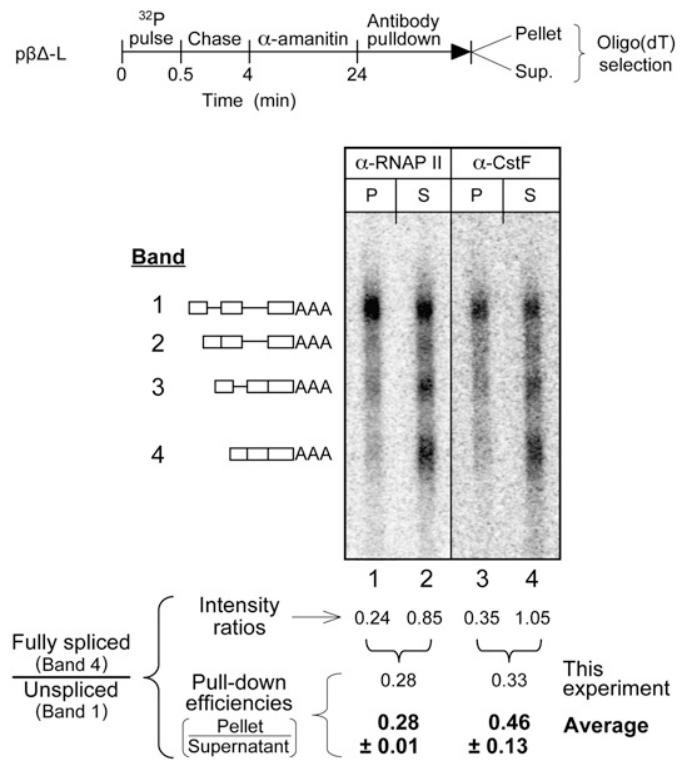

FIGURE 6. Splicing releases EDC-attached, polyadenylated RNA from the polymerase. Pull-down Method 2 was used. The average and range for two independent experiments is shown. 


\section{Splicing leads to remodeling of the 3 '-terminal EDC}

Although splicing reduced the ability of CstF to pull down polyadenylated RNA (Fig. 6, lanes 3-4), when we assayed RNA that was cleaved but not polyadenylated, splicing did not reduce the ability of CstF to pull this RNA down (Fig. 7, lanes 1,2, cf. bands 1 and 4). In fact, it is readily apparent from inspection of Figure 7, lanes 1 and 2, in the gel of Figure 7 that fully spliced RNA (Fig. 7, band 4) is actually pulled down more efficiently than its fully unspliced precursor (Fig. 7, band 1). Because this result was unexpected, we repeated the experiment using different antibodies. Whereas we used a polyclonal antibody raised against a peptide near the $\mathrm{C}$ terminus of CstF64 for lanes 1 and 2 of Figure 7, in the repeat experiment (Fig. 7, lanes 5,6) we employed a mixture of two monoclonals directed to internal epitopes of this protein (Wallace et al. 1999; Dass et al. 2001b). Again, it is apparent that fully spliced RNA (Fig. 7, band 4) is pulled down more efficiently than its fully unspliced precursor (Fig. 7, band 1). Since it seems unlikely that splicing might cause recruitment of CstF to RNA (thereby providing more epitopes that might increase pull-down efficiency), the simplest interpretation of these results is that the increased pull-down efficiency of fully spliced RNA arises from unmasking of the $64-\mathrm{kDa}$ subunit of CstF upon disruption of the splicing component of the EDC by splicing.

If the increase in pull-down efficiency caused by splicing of cleaved, nonpolyadenylated RNA is due to an effect on the 3'-terminal EDC, then this effect should be apparent primarily in the splicing of the second intron rather than the first. To test this prediction we examined the effects of splicing on pull-down efficiency for each intron separately. For example, the effect on pull-down efficiency of splicing the first intron is revealed by comparing the intensity of band 2 with that of band 1 in lanes 1 and 2 of Figure 7 (see the table to the right of the gel in Fig. 7). The results (beneath the gel) show that first intron splicing had little effect on the ability of CstF antibody to pull down the RNA, whereas when the second intron was spliced, the pull-down efficiency was dramatically increased (more than threefold for both types of antibody). Interestingly, the increase in epitope availability caused by splicing affects primarily the 64-kDa subunit of CstF since neither the $50-\mathrm{kDa}$ subunit nor the polymerase CTD to which it binds (Fong and Bentley 2001) experience a change of any significance in RNA pull-down efficiency as a result of splicing (Supplemental Fig. S4).

\section{DISCUSSION}

When processing is coupled to transcription in vitro the poly(A) signal on the emerging pre-mRNA becomes attached to RNA polymerase II during assembly of the CPA and remains attached even after cleavage at the poly(A) site

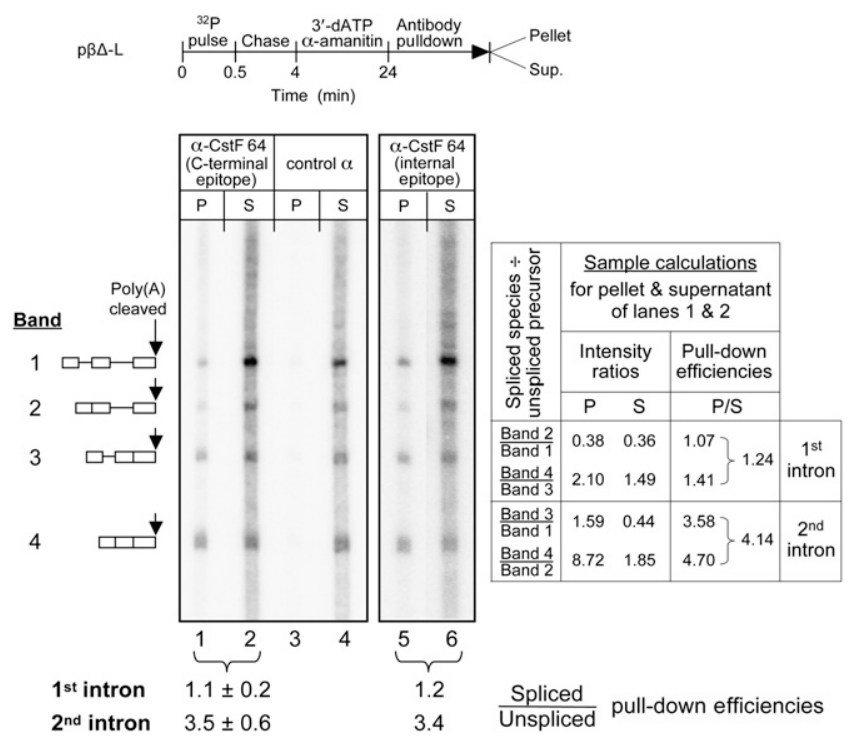

FIGURE 7. Splicing remodels the EDC. Pull-down Method 2 was used. The spliced/unspliced pull-down efficiencies were calculated as an average of the two ways in which the splicing of each intron can occur, as illustrated in the table. For lanes 1 and 2 the average and range for two independent experiments is given. Lanes 5 and 6 are from a different experiment.

(Figs. 2B, 3B; Supplemental Fig. S3; Adamson et al. 2005; Rigo et al. 2005). When the transcript contains introns, factors that bind the $3^{\prime}$ splice site of the $3^{\prime}$-terminal intron also participate in the early stages of this assembly process, forging interactions across the 3 '-terminal exon with the assembling CPA (Rigo and Martinson 2008). This yields, presumably, a terminal EDC (Berget 1995; Sharma et al. 2008) that spans the $3^{\prime}$-terminal exon and includes both splicing factors and the CPA, anchored to the CTD of the polymerase (Fig. 1A). This 3 '-terminal EDC can retain partially processed pre-mRNA on the polymerase even after the completion of $3^{\prime}$ end processing (Figs. 3A, 6, lane 1, band 1). Clearly, for transport out of the nucleus fully processed RNA must subsequently be released from the polymerase CTD, a step that provides an obvious opportunity for surveillance to ensure that only appropriately processed transcripts complete the transport pathway.

What triggers the release of RNA from the polymerase? When the RNA is attached to the polymerase only by a $\mathrm{CPA}$, some event triggered by the addition of a poly(A) tail leads to release (Fig. 4; Supplemental Fig. S1). There are two major restructurings of the CPA that are known to occur during poly(A) tail growth (Humphrey et al. 1987; Zarkower and Wickens 1987; Zhang and Cole 1987; Sheets and Wickens 1989; Bardwell and Wickens 1990; Wahle and Kühn 1997). The first occurs when the nascent poly(A) tail is only 10 or so adenosines long, and the initial copy of poly(A) binding protein II (PABII) joins the complex. At this time, an unidentified protein-probably CstF64-is repositioned on or ejected from the RNA (Bardwell and 
Wickens 1990; Wahle and Kühn 1997). The second restructuring event, which also requires PABII, occurs upon completion of the poly $(A)$ tail ( $\sim 200$ residues) and, in uncoupled processing experiments, appears to coincide with release of the polyadenylated RNA from what remains of the CPA (Humphrey et al. 1987; Zarkower and Wickens 1987; Zhang and Cole 1987).

Either of the major restructuring events described above is a good candidate for the trigger that releases the RNA from the polymerase. The second of the two events is an obvious possibility because that is when the polyadenylated RNA is ejected from the polyadenylation apparatus. However, it is also possible that the cleaved, oligoadenylated RNA is released from the polymerase together with part of the CPA during the first restructuring event, since this is when CstF, one of the direct links from the CPA to the CTD, appears to be lost. We are aware of only one study in which the first restructuring event can be distinguished from the second during coupled transcription and processing. This study was on the Chironomus Balbiani ring 1 locus where $\operatorname{poly}(\mathrm{A})$ site cleavage and the addition of the first 10 or so adenylate residues (the first restructuring event) appears to be roughly coincident with transcription termination (Baurén et al. 1998). Microdissection studies showed that almost immediately after this event the premRNA was transported away from the gene locus, where polyadenylation was then completed (Baurén et al. 1998). It is possible that the cleaved and oligoadenylated transcript leaves the DNA template together with the terminated polymerase during the first restructuring event, and then is released from the polymerase and the rest of the CPA upon completion of the poly(A) tail (see below).

While polyadenylation-associated restructuring is likely to be the trigger that releases CPA-attached RNA from the polymerase, most vertebrate pre-mRNAs are presumably attached by a terminal EDC, for which polyadenylation is not sufficient to effect release (Figs. 3A, 6, lane 1, band 1; Supplemental Fig. S2). For such RNA, attached by a terminal EDC, efficient release can be effected only by a combination of polyadenylation and splicing (Fig. 6, lane 1, band 4).

Figure 8 summarizes our data with an interpretive panel of freeze-frames. When a transcript contains no introns or splice sites, a CPA is assembled (Fig. 8, (1) which keeps the RNA anchored to the polymerase even after cleavage at the poly(A) site (Fig. 8, (2)). Subsequent polyadenylation (Fig. 8 , (3) then triggers a change in the CPA so that it releases the RNA from the polymerase (Fig. 8, (4)). When a premRNA contains introns, or at least a $3^{\prime}$ splice site, splicing factors assemble together with the CPA to form an EDC (Fig. 8, 5), from which the RNA is not released following either poly(A) site cleavage (Fig. 8, (6) or subsequent polyadenylation (Fig. 8, (7)). Nor does splicing cause significant release of the poly(A)site-cleaved RNA if it is not polyadenylated (Fig. 8, (6) $\rightarrow$ (2)). Only poly(A) addition fol- lowed by splicing causes significant release of the RNA from the polymerase (Fig. 8, (7) $\rightarrow$ [(3) $\rightarrow$ (4)).

Retention of pre-mRNA on the polymerase until the last exon is processed may be important for surveillance. ChIP analysis in Drosophila suggests that the transcription elongation complex is associated with the nuclear exosome (Andrulis et al. 2002). Therefore, incompletely processed RNA that lingers on the polymerase may be subject to increased exosomal scrutiny. Requiring completion of both splicing and $3^{\prime}$-end processing at the last exon in order to allow release maximizes the opportunity for surveillance.

Why is poly(A) addition sufficient to trigger release of RNA from the polymerase when the RNA is attached by the CPA (Fig. 8, (3)), but not when it is attached by the $3^{\prime}$-terminal EDC (Fig. 8, (7))? It is possible that the splicing factors in the $3^{\prime}$ EDC attach themselves to the polymerase in a way that can be reversed only by splicing. However, we consider this explanation to be unlikely. Although various splicing factors do associate with the polymerase (Yuryev et al. 1996; Kim et al. 1997; Zeng and Berget 2000; Emili et al. 2002; Robert et al. 2002; Kameoka et al. 2004; Ujvari and Luse 2004; Das et al. 2007), Figure 3, A and B, shows that a $3^{\prime}$ splice site mediates little attachment to the polymerase when the RNA lacks a poly(A)site-cleaved 3' end. Conversely, CPA-attached RNA, devoid of splice sites, binds well to the polymerase (Fig. 3B, lane 3; Fig. 4, lane 1; Supplemental Fig. S3), and cleaved but nonpolyadenylated RNA binds well whether the attachment is mediated by a full 3 '-terminal EDC (Fig. 5, bands 1,2) or by the smaller CPA that remains after splicing (Fig. 5, bands 3,4). Therefore, direct binding of $3^{\prime}$ splice site factors to the polymerase, though presumably important for recruitment, appears to add little to the final, stable, 3' EDC-mediated attachment of the RNA to the polymerase. This is exemplified by U2AF65 whose tight binding to the polymerase is weakened upon interaction with the nascent RNA (Ujvari and Luse 2004; Listerman et al. 2006).

To account for the ability of the 3 '-terminal EDC, but not the CPA, to retain the RNA after it has been polyadenylated, we favor a model in which the splicing factors in the terminal EDC constrain the CPA, stabilizing it, so as to prevent it from releasing the RNA in response to polyadenylation (Fig. 8, (7)). This is consistent with the implication from Figure 6 (lane 3, band 1) that polyadenylated, but unspliced, RNA remains associated with a substantially intact CPA, as evidenced by the ability of CstF to pull this RNA down. However, once splicing of the polyadenylated RNA occurs (Fig. 8, (7) $\rightarrow$ (3)), the splicing factors are released, and so also the constraints on the CPA. Now the CPA can respond to the polyadenylated state of the transcript by undergoing the change (presumably dismantling) that allows release of the spliced and polyadenylated transcript from the polymerase (Fig. 8, (4)).

A key element of this model is that splicing does not trigger, but rather licenses release of EDC-attached RNA 


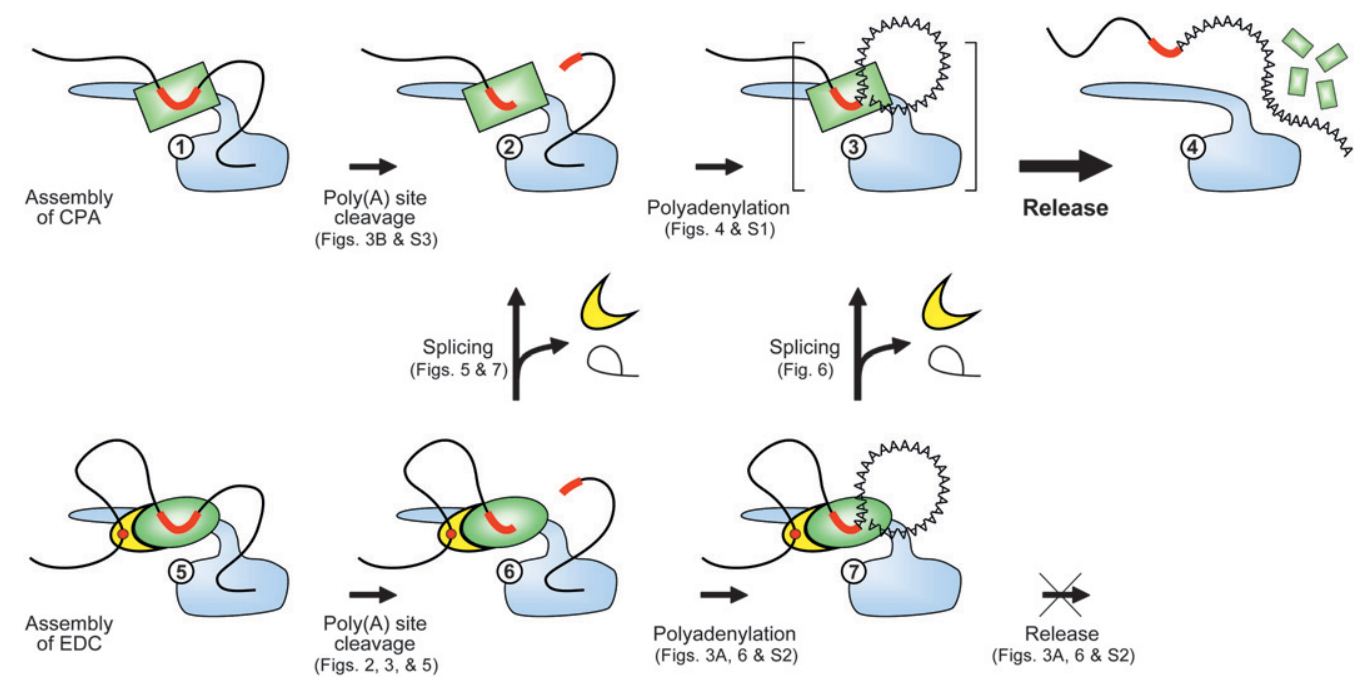

FIGURE 8. Polyadenylation releases EDC-attached mRNA from the polymerase in a process that must be licensed by splicing. The upper pathway in the model shows release from CPA attachment being triggered by polyadenylation. The lower pathway depicts splicing factors constraining the $\mathrm{CPA}$ and preventing this release until the splicing factors themselves are ejected by splicing.

from the polymerase (Fig. 8, (7) $\rightarrow$ (3)). The trigger is the poly(A) tail (Fig. 8, (3) $\rightarrow$ (4)). Thus, when elongation of the poly(A) tail was prevented by use of $3^{\prime}$-dATP, splicing did not lead to release (Fig. 8, (6) $\rightarrow$ (2)). The surprising CstF pulldown results of Figure 7 (and Supplemental Fig. S4) provided unexpected support for this interpretation. Lanes 1and 2 and 5 and 6 of Figure 7 (Supplemental Fig. S4, lanes $1,2)$ show that poly $(\mathrm{A})$ site-cleaved RNA was pulled down much more efficiently after splicing of the second intron (Fig. 8, (2) than before (Fig. 8, (6) by antibodies to various epitopes on CstF64. This result not only reinforces the idea that a CPA remains after disruption of the $3^{\prime}$ EDC by splicing, but also suggests that a general unmasking of CstF64 epitopes occurs when the splicing factors of the $3^{\prime}$ EDC are released. Although vertebrate CstF64 is not known to interact with splicing factors, and has never been found in association with any splicing complex (Chen et al. 2007), the extensive interactions of other cleavage and polyadenylation factors with splicing factors (see legend to Fig. $1 \mathrm{~A}, \mathrm{~B}$ ) could result in masking of CstF. A similar, though less pronounced increase in pull-down efficiency of second intron spliced transcripts when using antibodies to the body of the RNA polymerase (see Supplemental Fig. S4) suggests that splicing affects epitopes on the polymerase as well. Regardless of the details, the apparent unmasking of CstF64, and probably also of the polymerase, by splicing illustrates the global reach of structural effects involving splicing factors within the $3^{\prime}$-terminal EDC. This lends credibility to the idea that these interactions constrain the $\mathrm{CPA}$, when it is part of an $\mathrm{EDC}$, and prevent it from releasing the transcript in response to addition of the poly(A) tail, until licensed by splicing.

Additional evidence that the splicing factors of the $3^{\prime}$ terminal EDC stabilize the CPA in a particular functional state was revealed by the finding that mutation of the 3' splice site in the pSV40E/L construct, which allows a CPA but not an EDC to form, results in altered poly(A) tail length control (Fig. 4; Supplemental Fig. S1). Although the overall efficiency of cleavage/polyadenylation was only slightly affected (10\%-15\% decrease, data not shown), the CPA's ability to control poly(A) tail length was dramatically altered, so that half of the cleaved RNAs received poly(A) tails that were substantially longer than normal (Supplemental Fig. S1). A role for the $3^{\prime}$ splice site in poly(A) tail length control has not been observed previously. Probably this is because crowding agents like polyvinyl alcohol (PVA) are generally used in cleavage/polyadenylation experiments. PVA is known to be able to restore certain aspects of coupling to uncoupled systems (Rigo and Martinson 2008), and we have found that PVA can restore poly(A) tail length control to 3'end processing that has been uncoupled from splicing by a $3^{\prime}$ splice site mutation (data not shown). Thus, either splicing factors or PVA can stabilize the CPA to permit normal poly(A) tail length control in vitro.

In this paper we have focused on the role of the CPA and the 3 '-terminal EDC in attaching RNA to the polymerase. Of course, upstream introns also contribute to polymerase binding through spliceosomal/non-3'-EDC attachments (Zeng and Berget 2000), interactions which may assist exon-defined splicing through the tethering of exons to the CTD (Zeng and Berget 2000; Dye et al. 2006). However, under coupled transcription-processing conditions the overall contribution of these interactions to polymerase binding is much less than that of the 3 '-terminal EDC (Fig. 5; Supplemental Fig. S3), and they have not been included in the model of Figure 8.

No previous studies have examined the mechanism by which mRNA is released from the polymerase once it has 
undergone transcription-coupled processing. However, a number of studies in vivo have examined release from the vicinity of the gene. Our finding that human $\beta$-globin transcripts must be both spliced and $3^{\prime}$-end processed in order to be released from the polymerase is consistent, for example, with FISH studies showing that human $\beta$-globin gene mutants with impaired second intron splicing or impaired 3'-end processing tend to be retained in "dots" at or near the site of transcription (Custódio et al. 1999). This retention could reflect the failure of RNA to be released from polymerases that remain attached to the "nuclear matrix" following termination of transcription (Custódio et al. 1999).

The retention of RNA in dots also occurs in yeast (Schmid and Jensen 2008). However, in yeast, steps in transport subsequent to release from the polymerase appear to be principally responsible for generating the dots (Abruzzi et al. 2006; Chekanova et al. 2008). Release from the polymerase, studied in a mammalian system here, may therefore be of less importance in yeast than in mammals. This could reflect less robust attachment of transcripts to the polymerase in yeast, as transcription, processing and transport are not as tightly coupled in yeast as in mammals (Licatalosi et al. 2002; Jensen et al. 2003; Dower et al. 2004). In mammals, the polymerase is known to be a required participant in the release of processed mRNA from the site of transcription (Custódio et al. 2007). A mutant mouse polymerase with a CTD truncated to $60 \%$ of its normal length can fully support mRNA processing but cannot support release of the RNA from dots (Custódio et al. 2007). Since the yeast CTD is very similar to and even shorter than the CTD in this mouse truncation mutant the possibility exists that this function of the CTD does not exist, and is not required, in yeast. Interestingly, the portion of the mouse CTD missing in the truncation mutant, and that is required for release, is significantly different from the yeast CTD but almost completely conserved among mammals (Barron-Casella and Corden 1992). Thus, the mammalian CTD may be more intimately involved in orchestrating the release of new RNA into the transport pathway than is the case in yeast.

Several years ago Bird et al. (2005) observed that releasing $\beta$-globin pre-mRNA from the DNA template by ribozyme cutting in the $3^{\prime}$ flank could enhance splicing. Based on this they proposed that splicing near the $3^{\prime}$ end is normally prevented until release of the transcript from the DNA template has occurred. Our results now show that this release from the template must reflect transcription termination since RNA with unspliced 3' introns remains attached to the polymerase (Fig. 6). Interestingly, Baurén et al. (1998) found, not only (as mentioned earlier) that cleaved and oligoadenylated RNA moves rapidly away from the BR1 gene locus following transcription termination, but also that this coincides with a burst of rapid splicing. Presumably, until this splicing occurs, the oligoadenylated
RNA remains attached to the terminated polymerase. Release from the polymerase may then occur either immediately after splicing (if it is the first CPA restructuring event that is required for release) or upon completion of full polyadenylation (if it is the second CPA restructuring event that is required). Note that in the latter case the sequence of events leading to BR1 release would follow the first branch (splicing first) of the pathway shown in Figure 8, whereas our results for $\beta$-globin follow the second branch (polyadenylation first) (see Figure 6; Rigo and Martinson 2008).

\section{MATERIALS AND METHODS}

\section{Plasmids}

The plasmids $\mathrm{pSV} 40 \mathrm{E} / \mathrm{L}$ and $\mathrm{p} \beta \Delta$-L have been described previously (Rigo et al. 2005; Rigo and Martinson 2008). Both contain a transcription unit that begins with the SV40 early promoter and ends with the SV40 late poly(A) signal. The nonsplicing construct, pSV40E/L, contains sequences flanking the terminal $3^{\prime}$ splice site of the chicken $\beta^{\mathrm{H}}$-globin gene but does not contain any $5^{\prime}$ splice site. The splicing construct, $\mathrm{p} \beta \Delta-\mathrm{L}$, contains the body of the human $\beta$-globin gene but with a shortened second intron.

\section{Coupled processing assay}

HeLa nuclear extract was prepared as described previously (Flaherty et al. 1997; Tran et al. 2001; Rigo et al. 2005) except that the volume of high salt buffer $\mathrm{C}$ added was $0.425 \mathrm{PNV}$ (Rigo and Martinson 2008). For a detailed protocol visit http://www. biochemistry.ucla.edu/biochem/Faculty/Martinson. A typical assay was performed as previously described (Rigo and Martinson 2008). Briefly, the assay began with $4 \mu \mathrm{L}$ of nuclear extract which was preincubated with DNA, then pulsed with $\left[\alpha-{ }^{32} \mathrm{P}\right] \mathrm{CTP}$, chased with a high concentration of nonradiolabeled CTP, and finally treated with $\alpha$-amanitin during the processing phase of the reaction (final reaction volume: $13.5 \mu \mathrm{L}$ ). Many experiments required $3^{\prime}$ dATP to block poly(A) tail growth. Since $3^{\prime}$-dATP interferes with transcription, for consistency we also added $\alpha$-amanitin (which does not affect coupled processing) to all samples. This ensured that transcription itself was not a variable in any of the experiments. When oligo(dT) selection was used it was carried out in one round using a Poly(A) Purist MAG kit (Ambion) immediately prior to gel electrophoresis.

\section{Antibody pull-downs}

These were done as previously described (Rigo et al. 2005) except that the beads were washed one time with dialysis buffer after washing with phosphate-buffered saline (PBS). Pull-downs were performed using the polyclonal antibodies N-20 and C-20 (Santa Cruz Biotechnology) raised against a peptide near the $\mathrm{N}$ terminus of the RNA polymerase II large subunit or near the C terminus of CstF64, respectively. For Figure 7 a CstF64 pull-down was also carried out using a mixture of monoclonal antibodies (3A7 and 6A9, gift from Clint MacDonald, Texas Tech University Health Sciences Center) (see Wallace et al. 1999) whose epitopes map to internal sequences of CstF64 (Dass et al. 2001b). Control 
antibodies, chosen for arbitrary reasons, were goat normal IgG (Santa Cruz Biotechnology) for Figure 2, anti-EIB (2A6, gift from Clint MacDonald, Texas Tech University Health Sciences Center) (see Dass et al. 2001a) for Figure 3, or anti-U2AF65 (N-14, Santa Cruz Biotechnology) for Figures 5 and 7. The polymerase N-20 and CstF C-20 pull-downs were done in three different ways. Method 1 used $16 \mu \mathrm{g}$ of antibody and $80 \mu \mathrm{L}$ of protein $\mathrm{G}$ beads and after the pulldown the beads were washed with transcription buffer that consisted of 4.8\% glycerol, $4.8 \mathrm{mM}$ HEPES ( $\mathrm{pH} 7.9$ ), $24 \mathrm{mM} \mathrm{KCl}, 48 \mu \mathrm{M}$ EDTA, $120 \mu \mathrm{M}$ DTT, and $24 \mu \mathrm{M}$ phenylmethylsulfonyl fluoride. Method 2 used $4 \mu \mathrm{g}$ of antibody and 20 $\mu \mathrm{L}$ of protein $\mathrm{G}$ beads and after the pulldown the beads were washed with PBS. Method 3 used $8 \mu \mathrm{g}$ of antibody and $40 \mu \mathrm{L}$ of protein $G$ beads and after the pulldown the beads were washed with transcription buffer. The pull-downs were for $20 \mathrm{~min}$ and the wash was combined with the supernatant except for Figures $2 \mathrm{~B}$ and $3 \mathrm{~B}$ where the washes were loaded separately (not shown because they contained negligible amounts of RNA) and Figure $2 \mathrm{C}$ where the wash was discarded.

\section{SUPPLEMENTAL MATERIAL}

Supplemental material can be found at http://www.rnajournal.org.

\section{ACKNOWLEDGMENTS}

We thank Amir Kazerouninia and Anita Nag for important discussions during the course of this work, Mariano Garcia-Blanco for useful comments, Clint MacDonald for providing the monoclonal antibodies 3A7, 6A9, and 2A6, and the Jonsson Cancer Center Foundation and the NIH (Grant GM50863) for support.

Received October 7, 2008; accepted January 23, 2009.

\section{REFERENCES}

Abruzzi, K.C., Belostotsky, D.A., Chekanova, J.A., Dower, K., and Rosbash, M. 2006. 3'-End formation signals modulate the association of genes with the nuclear periphery as well as mRNP dot formation. EMBO J. 25: 4253-4262.

Adamson, T.E., Shutt, D.C., and Price, D.H. 2005. Functional coupling of cleavage and polyadenylation with transcription of mRNA. J. Biol. Chem. 280: 32262-32271.

Andrulis, E.D., Werner, J., Nazarian, A., Erdjument-Bromage, H., Tempst, P., and Lis, J.T. 2002. The RNA processing exosome is linked to elongating RNA polymerase II in Drosophila. Nature 420: 837-841.

Antoniou, M., Geraghty, F., Hurst, J., and Grosveld, F. 1998. Efficient $3^{\prime}$-end formation of human beta-globin mRNA in vivo requires sequences within the last intron but occurs independently of the splicing reaction. Nucleic Acids Res. 26: 721-729.

Bardwell, V.J. and Wickens, M. 1990. Polyadenylation-specific complexes undergo a transition early in the polymerization of a poly(A) tail. Mol. Cell. Biol. 10: 295-302.

Barron-Casella, E. and Corden, J.L. 1992. Conservation of the mammalian RNA polymerase II largest-subunit C-terminal domain. J. Mol. Evol. 35: 405-410.

Baurén, G., Belikov, S., and Wieslander, L. 1998. Transcriptional termination in the Balbiani ring 1 gene is closely coupled to $3^{\prime}$-end formation and excision of the $3^{\prime}$-terminal intron. Genes \& Dev. 12: 2759-2769.
Berget, S.M. 1995. Exon recognition in vertebrate splicing. J. Biol. Chem. 270: 2411-2414.

Bird, G., Zorio, D.A., and Bentley, D.L. 2004. RNA polymerase II carboxy-terminal domain phosphorylation is required for cotranscriptional pre-mRNA splicing and 3'-end formation. Mol. Cell. Biol. 24: 8963-8969.

Bird, G., Fong, N., Gatlin, J.C., Farabaugh, S., and Bentley, D.L. 2005. Ribozyme cleavage reveals connections between mRNA release from the site of transcription and Pre-mRNA processing. Mol. Cell 20: $747-758$

Black, D.L. 2003. Mechanisms of alternative pre-messenger RNA splicing. Annu. Rev. Biochem. 72: 291-336.

Brown, K.M. and Gilmartin, G.M. 2003. A mechanism for the regulation of Pre-mRNA 3' processing by human cleavage factor $\mathrm{I}_{\mathrm{m}}$. Mol. Cell 12: 1467-1476.

Chao, L.C., Jamil, A., Kim, S.J., Huang, L., and Martinson, H.G. 1999. Assembly of the cleavage and polyadenylation apparatus requires about 10 seconds in vivo and is faster for strong than for weak poly(A) sites. Mol. Cell. Biol. 19: 5588-5600.

Chekanova, J.A., Abruzzi, K.C., Rosbash, M., and Belostotsky, D.A. 2008. Sus1, Sac3, and Thp1 mediate post-transcriptional tethering of active genes to the nuclear rim as well as to non-nascent mRNP. RNA 14: 1-12.

Chen, Y.I., Moore, R.E., Ge, H.Y., Young, M.K., Lee, T.D., and Stevens, S.W. 2007. Proteomic analysis of in vivo-assembled premRNA splicing complexes expands the catalog of participating factors. Nucleic Acids Res. 35: 3928-3944.

Connelly, S. and Manley, J.L. 1988. A functional mRNA polyadenylation signal is required for transcription termination by RNA polymerase II. Genes \& Dev. 2: 440-452.

Cooke, C. and Alwine, J.C. 1996. The cap and the 3' splice site similarly affect polyadenylation efficiency. Mol. Cell. Biol. 16: 25792584.

Custódio, N., Carmo-Fonseca, M., Geraghty, F., Pereira, H.S., Grosveld, F., and Antoniou, M. 1999. Inefficient processing impairs release of RNA from the site of transcription. EMBO J. 18: 2855-2866.

Custódio, N., Vivo, M., Antoniou, M., and Carmo-Fonseca, M. 2007. Splicing- and cleavage-independent requirement of RNA polymerase II CTD for mRNA release from the transcription site. J. Cell Biol. 179: 199-207.

Das, R., Yu, J., Zhang, Z., Gygi, M.P., Krainer, A.R., Gygi, S.P., and Reed, R. 2007. SR proteins function in coupling RNAP II transcription to pre-mRNA splicing. Mol. Cell 26: 867-881.

Dass, B., Attaya, E.N., Michelle Wallace, A., and MacDonald, C.C. 2001a. Overexpression of the CstF-64 and CPSF-160 polyadenylation protein messenger RNAs in mouse male germ cells. Biol. Reprod. 64: 1722-1729.

Dass, B., McMahon, K.W., Jenkins, N.A., Gilbert, D.J., Copeland, N.G., and MacDonald, C.C. 2001b. The gene for a variant form of the polyadenylation protein CstF-64 is on chromosome 19 and is expressed in pachytene spermatocytes in mice. J. Biol. Chem. 276: 8044-8050.

de Vries, H., Ruegsegger, U., Hubner, W., Friedlein, A., Langen, H., and Keller, W. 2000. Human pre-mRNA cleavage factor $\mathrm{II}_{\mathrm{m}}$ contains homologs of yeast proteins and bridges two other cleavage factors. $E M B O$ J. 19: 5895-5904.

Dower, K., Kuperwasser, N., Merrikh, H., and Rosbash, M. 2004. A synthetic A tail rescues yeast nuclear accumulation of a ribozymeterminated transcript. RNA 10: 1888-1899.

Dye, M.J., Gromak, N., and Proudfoot, N.J. 2006. Exon tethering in transcription by RNA polymerase II. Mol. Cell 21: 849-859.

Dye, M.J. and Proudfoot, N.J. 1999. Terminal exon definition occurs cotranscriptionally and promotes termination of RNA polymerase II. Mol. Cell 3: 371-378.

Emili, A., Shales, M., McCracken, S., Xie, W., Tucker, P.W., Kobayashi, R., Blencowe, B.J., and Ingles, C.J. 2002. Splicing and transcription-associated proteins PSF and $\mathrm{p} 54 \mathrm{nrb} / \mathrm{nonO}$ bind to the RNA polymerase II CTD. RNA 8: 1102-1111. 
Flaherty, S.M., Fortes, P., Izaurralde, E., Mattaj, I.W., and Gilmartin, G.M. 1997. Participation of the nuclear cap binding complex in pre-mRNA 3' processing. Proc. Natl. Acad. Sci. 94: 11893-11898.

Fong, N. and Bentley, D.L. 2001. Capping, splicing, and 3' processing are independently stimulated by RNA polymerase II: Different functions for different segments of the CTD. Genes \& Dev. 15: 1783-1795.

Hirose, Y. and Manley, J.L. 1998. RNA polymerase II is an essential mRNA polyadenylation factor. Nature 395: 93-96.

Humphrey, T., Christofori, G., Lucijanic, V., and Keller, W. 1987. Cleavage and polyadenylation of messenger RNA precursors in vitro occurs within large and specific $3^{\prime}$ processing complexes. EMBO J. 6: 4159-4168.

Jensen, T.H., Dower, K., Libri, D., and Rosbash, M. 2003. Early formation of mRNP. License for export or quality control? Mol. Cell 11: 1129-1138.

Johnson, C., Primorac, D., McKinstry, M., McNeil, J., Rowe, D., and Lawrence, J.B. 2000. Tracking COL1A1 RNA in osteogenesis imperfecta. Splice-defective transcripts initiate transport from the gene but are retained within the SC35 domain. J. Cell Biol. 150: $417-432$.

Kameoka, S., Duque, P., and Konarska, M.M. 2004. p54 ${ }^{\text {nrb }}$ associates with the $5^{\prime}$ splice site within large transcription/splicing complexes. EMBO J. 23: 1782-1791.

Kaufmann, I., Martin, G., Friedlein, A., Langen, H., and Keller, W. 2004. Human Fip1 is a subunit of CPSF that binds to U-rich RNA elements and stimulates poly(A) polymerase. EMBO J. 23: 616-626.

Kim, E., Du, L., Bregman, D.B., and Warren, S.L. 1997. Splicing factors associate with hyperphosphorylated RNA polymerase II in the absence of pre-mRNA. J. Cell Biol. 136: 19-28.

Kim, H. and Lee, Y. 2001. Interaction of poly(A) polymerase with the $25-\mathrm{kDa}$ subunit of cleavage factor I. Biochem. Biophys. Res. Commun. 289: 513-518.

Kyburz, A., Friedlein, A., Langen, H., and Keller, W. 2006. Direct interactions between subunits of CPSF and the U2 snRNP contribute to the coupling of pre-mRNA $3^{\prime}$ end processing and splicing. Mol. Cell 23: 195-205.

Li, Y., Chen, Z.Y., Wang, W., Baker, C.C., and Krug, R.M. 2001. The $3^{\prime}$-end-processing factor CPSF is required for the splicing of singleintron pre-mRNAs in vivo. RNA 7: 920-931.

Licatalosi, D.D., Geiger, G., Minet, M., Schroeder, S., Cilli, K., McNeil, J.B., and Bentley, D.L. 2002. Functional interaction of yeast pre-mRNA $3^{\prime}$ end processing factors with RNA polymerase II. Mol. Cell 9: 1101-1111.

Listerman, I., Sapra, A.K., and Neugebauer, K.M. 2006. Cotranscriptional coupling of splicing factor recruitment and precursor messenger RNA splicing in mammalian cells. Nat. Struct. Mol. Biol. 13: 815-822.

McCracken, S., Fong, N., Yankulov, K., Ballantyne, S., Pan, G., Greenblatt, J., Patterson, S.D., Wickens, M., and Bentley, D.L. 1997. The C-terminal domain of RNA polymerase II couples mRNA processing to transcription. Nature 385: 357-361.

Meinhart, A. and Cramer, P. 2004. Recognition of RNA polymerase II carboxy-terminal domain by 3 '-RNA-processing factors. Nature 430: $223-226$

Millevoi, S., Loulergue, C., Dettwiler, S., Karaa, S.Z., Keller, W., Antoniou, M., and Vagner, S. 2006. An interaction between U2AF 65 and $\mathrm{CF} \mathrm{I}_{\mathrm{m}}$ links the splicing and $3^{\prime}$ end processing machineries. EMBO J. 25: 4854-4864.

Morillon, A., O’Sullivan, J., Azad, A., Proudfoot, N., and Mellor, J. 2003. Regulation of elongating RNA polymerase II by forkhead transcription factors in yeast. Science 300: 492-495.

Murthy, K.G. and Manley, J.L. 1995. The 160-kDa subunit of human cleavage-polyadenylation specificity factor coordinates pre-mRNA 3'-end formation. Genes \& Dev. 9: 2672-2683.

Nag, A., Narsinh, K., Kazerouninia, A., and Martinson, H.G. 2006. The conserved AAUAAA hexamer of the poly(A) signal can act alone to trigger a stable decrease in RNA polymerase II transcription velocity. RNA 12: 1534-1544.

Nag, A., Narsinh, K., and Martinson, H.G. 2007. The poly(A)dependent transcriptional pause is mediated by CPSF acting on the body of the polymerase. Nat. Struct. Mol. Biol. 14: 662-669.

Niwa, M. and Berget, S.M. 1991. Mutation of the AAUAAA polyadenylation signal depresses in vitro splicing of proximal but not distal introns. Genes \& Dev. 5: 2086-2095.

Niwa, M., Rose, S.D., and Berget, S.M. 1990. In vitro polyadenylation is stimulated by the presence of an upstream intron. Genes \& Dev. 4: $1552-1559$.

Orozco, I.J., Kim, S.J., and Martinson, H.G. 2002. The poly(A) signal, without the assistance of any downstream element, directs RNA polymerase II to pause in vivo and then to release stochastically from the template. J. Biol. Chem. 277: 42899-42911.

Qu, X., Perez-Canadillas, J.M., Agrawal, S., De Baecke, J., Cheng, H., Varani, G., and Moore, C. 2006. The C-terminal domains of vertebrate CstF-64 and its yeast orthologue Rna15 form a new structure critical for mRNA $3^{\prime}$-end processing. J Biol Chem. 283: 2101-2115.

Reed, R. 2003. Coupling transcription, splicing, and mRNA export. Curr. Opin. Cell Biol. 15: 326-331.

Rigo, F. and Martinson, H.G. 2008. Functional coupling of last intron splicing and $3^{\prime}$-end processing to transcription in vitro: The poly(A) signal couples to splicing before committing to cleavage. Mol. Cell. Biol. 28: 849-862.

Rigo, F., Kazerouninia, A., Nag, A., and Martinson, H.G. 2005. The RNA tether from the poly(A) signal to the polymerase mediates coupling of transcription to cleavage and polyadenylation. Mol. Cell 20: 733-745.

Robert, F., Blanchette, M., Maes, O., Chabot, B., and Coulombe, B. 2002. A human RNA polymerase II-containing complex associated with factors necessary for spliceosome assembly. J. Biol. Chem. 277: 9302-9306.

Ruegsegger, U., Beyer, K., and Keller, W. 1996. Purification and characterization of human cleavage factor $\mathrm{I}_{\mathrm{m}}$ involved in the $3^{\prime}$ end processing of messenger RNA precursors. J. Biol. Chem. 271: 6107-6113.

Ryan, K., Murthy, K.G., Kaneko, S., and Manley, J.L. 2002. Requirements of the RNA polymerase II C-terminal domain for reconstituting pre-mRNA 3' cleavage. Mol. Cell. Biol. 22: 1684-1692.

Schmid, M. and Jensen, T.H. 2008. Quality control of mRNP in the nucleus. Chromosoma 117: 419-429.

Sharma, S., Kohlstaedt, L.A., Damianov, A., Rio, D.C., and Black, D.L. 2008. Polypyrimidine tract binding protein controls the transition from exon definition to an intron defined spliceosome. Nat. Struct. Mol. Biol. 15: 183-191.

Sheets, M.D. and Wickens, M. 1989. Two phases in the addition of a poly(A) tail. Genes \& Dev. 3: 1401-1412.

Tran, D.P., Kim, S.J., Park, N.J., Jew, T.M., and Martinson, H.G. 2001. Mechanism of poly(A) signal transduction to RNA polymerase II in vitro. Mol. Cell. Biol. 21: 7495-7508.

Ujvari, A. and Luse, D.S. 2004. Newly Initiated RNA encounters a factor involved in splicing immediately upon emerging from within RNA polymerase II. J. Biol. Chem. 279: 49773-49779.

Vagner, S., Vagner, C., and Mattaj, I.W. 2000. The carboxyl terminus of vertebrate poly (A) polymerase interacts with U2AF 65 to couple 3 '-end processing and splicing. Genes \& Dev. 14: 403-413.

Venkataraman, K., Brown, K.M., and Gilmartin, G.M. 2005. Analysis of a noncanonical poly(A) site reveals a tripartite mechanism for vertebrate poly(A) site recognition. Genes \& Dev. 19: 1315-1327.

Wahle, E. and Kühn, U. 1997. The mechanism of $3^{\prime}$ cleavage and polyadenylation of eukaryotic pre-mRNA. Prog. Nucleic Acid Res. Mol. Biol. 57: 41-71.

Wallace, A.M., Dass, B., Ravnik, S.E., Tonk, V., Jenkins, N.A., Gilbert, D.J., Copeland, N.G., and MacDonald, C.C. 1999. Two distinct forms of the 64,000 $\mathrm{Mr}$ protein of the cleavage stimulation factor are expressed in mouse male germ cells. Proc. Natl. Acad. Sci. 96: 6763-6768. 
West, S., Proudfoot, N.J., and Dye, M.J. 2008. Molecular dissection of mammalian RNA polymerase II transcriptional termination. Mol. Cell 29: 600-610.

Whitelaw, E. and Proudfoot, N. 1986. $\alpha$-Thalassaemia caused by a poly(A) site mutation reveals that transcriptional termination is linked to $3^{\prime}$ end processing in the human $\alpha 2$ globin gene. EMBO J. 5: 2915-2922.

Yuryev, A., Patturajan, M., Litingtung, Y., Joshi, R.V., Gentile, C., Gebara, M., and Corden, J.L. 1996. The C-terminal domain of the largest subunit of RNA polymerase II interacts with a novel set of serine/arginine-rich proteins. Proc. Natl. Acad. Sci. 93: 6975-6980.

Zarkower, D. and Wickens, M. 1987. Specific pre-cleavage and postcleavage complexes involved in the formation of SV40 late mRNA $3^{\prime}$ termini in vitro. EMBO J. 6: 4185-4192.
Zeng, C. and Berget, S.M. 2000. Participation of the C-terminal domain of RNA polymerase II in exon definition during premRNA splicing. Mol. Cell. Biol. 20: 8290-8301.

Zhang, F. and Cole, C.N. 1987. Identification of a complex associated with processing and polyadenylation in vitro of herpes simplex virus type 1 thymidine kinase precursor RNA. Mol. Cell. Biol. 7: 3277-3286.

Zhang, Z. and Gilmour, D.S. 2006. Pcf11 is a termination factor in Drosophila that dismantles the elongation complex by bridging the CTD of RNA polymerase II to the nascent transcript. Mol. Cell 21: 65-74.

Zhao, J., Hyman, L., and Moore, C. 1999. Formation of mRNA 3' ends in eukaryotes: Mechanism, regulation, and interrelationships with other steps in mRNA synthesis. Microbiol. Mol. Biol. Rev. 63: 405-445. 

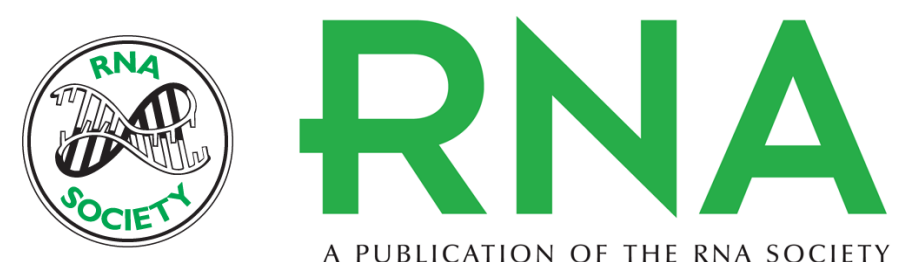

A PUBLICATION OF THE RNA SOCIETY

\title{
Polyadenylation releases mRNA from RNA polymerase II in a process that is licensed by splicing
}

\author{
Frank Rigo and Harold G. Martinson
}

RNA 2009 15: 823-836 originally published online March 20, 2009

Access the most recent version at doi:10.1261/rna.1409209

\section{Supplemental http://rnajournal.cshlp.org/content/suppl/2009/03/23/rna.1409209.DC1 \\ Material}

References This article cites 75 articles, 41 of which can be accessed free at:

http://rnajournal.cshlp.org/content/15/5/823.full.html\#ref-list-1

\section{License}

Email Alerting Receive free email alerts when new articles cite this article - sign up in the box at the Service top right corner of the article or click here.

To subscribe to RNA go to:

http://rnajournal.cshlp.org/subscriptions 